\title{
Adrenal hypoplasia congenita in identical twins
}

\author{
Alia M. Al Amer, MD, Khloud M. Al Rubaya, MD, Ali S. Alzahrani, MD.
}

\begin{abstract}
نستعرض هنا حالة أشقاء توأم من بويضة واحدة راجعَوا في أعمار

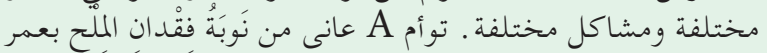

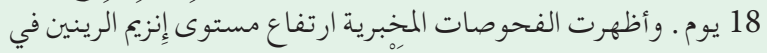

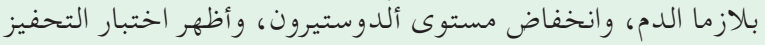

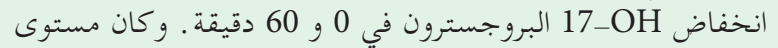

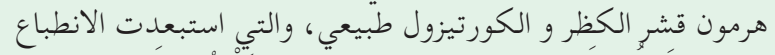

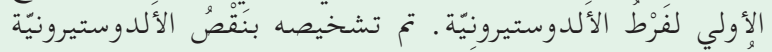

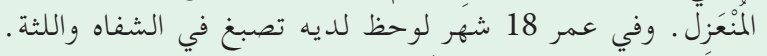

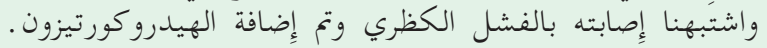

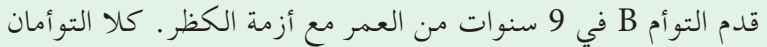

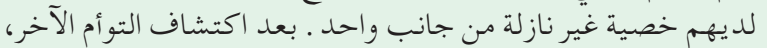

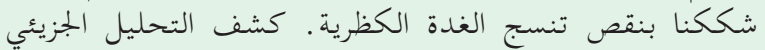

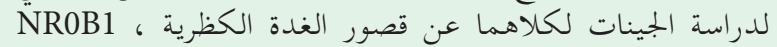

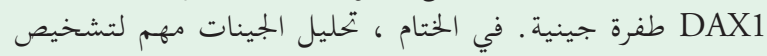
AHC
\end{abstract}

We are presenting a monozygotic twin brothers presented at different ages with different presentations. Twin-A presented at age of 18 days with salt losing crisis. Investigations revealed high plasma renin with low-normal aldosterone. Adrenocorticotropic hormone stimulation test revealed low $17-\mathrm{OH}$ progesterone at 0 and 60 minutes. Adrenocorticotropic hormone level and serum cortisol were normal, which excluded initial impression of congenital adrenal hyperplasia. He was diagnosed to have isolated primary hypoaldosteronism. At age of 18 months, he was noticed to have hyperpigmentation of lips and gum. Adrenal failure was suspected, and hydrocortisone was added. Twin-B presented at 9 years and 6 months of age with adrenal crisis. Both were having unilateral undescended testis. Adrenal hypoplasia congenita (AHC) was suspected after his twin's presentation. Molecular analysis for gene study for both of them revealed adrenal insufficiency, NR0B1 (DAX1) gene mutation. In conclusion, gene analysis is important for the diagnosis of $\mathrm{AHC}$ and for genetic counseling.

Saudi Med J 2019; Vol. 40 (1): 87-92 doi: 10.15537/smj.2019.1.23337
From the Unit of Pediatric Endocrinology and Diabetes (Al Amer, Al Rubaya), Maternity and Children Hospital, Dammam, and from the Department of Medicine (Alzahrani), King Faisal Specialist Hospital and Research Center, Riyadh, Kingdom of Saudi Arabia

Received 6th August 2018. Accepted 28th November 2018.

Address correspondence and reprint request to: Dr. Alia M. Al Amer, Unit of Pediatric Endocrinology and Diabetes, Maternity and Children Hospital, Dammam, Kingdom of Saudi Arabia.E-mail: draliaalamer@hotmail.com ORCID ID: orcid.org/0000-0002-2170-0650

$\mathrm{X}^{-1}$ -linked congenital adrenal hypoplasia (CAH) is a very uncommon genetic disorder that is caused by an abnormality in the DAX-1 gene (dosage-sensitive sex reversal-adrenal hypoplasia congenita critical region on the $\mathrm{X}$ chromosome, gene 1 [NR0B1]), ${ }^{1}$ was first introduced in 1948. Mutations in this gene were proved as the cause of the X-linked congenital adrenal hypoplasia in $1994 .^{5}$

The DAX-1 gene consists of 2 exons and a single 3.4-kilobase intron. The protein coded by this gene is one of the nuclear receptor family. DAX-1 gene is expressed in many glands including the adrenals, gonads, hypothalamus, and pituitary gland. It controls their development and function. Adrenal hypoplasia congenita (AHC) is a rare disorder inherited as an autosomal recessive or X-linked disease. ${ }^{2}$ The X-linked AHC is due to DAX-1 gene mutation or deletion. The typical presentation in boys with X-linked AHC during neonatal period or childhood, is primary adrenal insufficiency. Later in life, they may develop different puberty disorders. Classically, delayed or absence puberty due to hypogonadotropic hypogonadism (HHG). Rarely, they may proceed to normal puberty or may develop precocious puberty (peripheral, central, or adrenocorticotropic hormone-dependent). ${ }^{2,3}$

Case Report. Patient information twin-A. He was born on 13th February 2006, at 37 weeks of gestation to a 39-year-old gravida 6 para 6 mother after uncomplicated twin pregnancy. The parents were second degree cousins of Saudi origins. He has 2 elder brothers and 3 sisters, all 
are alive and healthy. His birth weight was $2.0 \mathrm{~kg}$, body length was $46 \mathrm{~cm}$, and head circumference was $32 \mathrm{~cm}$. $\mathrm{He}$ was discharged with his mother in good condition after 3 days of admission to the nursery for observation.

Clinical findings. At the age of 18 days, he was presented to the emergency department with history of vomiting, poor feeding, and decreased activity with failure to thrive. On physical examination, his weight was $1.66 \mathrm{~kg}$, blood pressure (BP) was $67 / 51 \mathrm{mmHg}$, heart rate was $160 / \mathrm{min}$, temperature was $36.2^{\circ} \mathrm{C}$, and respiratory rate (RR) was $58 / \mathrm{min}$. He was dehydrated, not dysmorphic with no evidence of hyperpigmentation. Normal systemic examination, with normal male genitalia (Figure 1).

Diagnostic assessment. He was admitted to neonatal intensive care unit with impression of sepsis. Laboratory tests showed hyponatremia $128 \mathrm{mmol} / \mathrm{L}$ with hyperkalemia $6.2 \mathrm{mmol} / \mathrm{L}$. Septic workup was carried out and were awaited. He was managed with intravenous fluids and antibiotics. He was noticed to have persisted hyponatremia and hyperkalemia, therefore endocrine consultation was requested. A provisional diagnosis of congenital adrenal hyperplasia was made as it is the most common cause of salt wasting at this age group. His endocrinological data revealed unelevated adrenocorticotropic hormone (ACTH), serum aldosterone low-normal while plasma renin was very high. Adrenocorticotropic hormone stimulation test was carried out with $0.25 \mathrm{mg}$ synthectin which showed normal cortisol response at 60 minutes. Seventeen hydroxyprogesterone, dehydroepiandrosterone sulfate (DHEAS), and testosterone were normal. Chromosomal study showed 46 XY (Table 1).

Therapeutic intervention. These results ruled out $\mathrm{CAH}$. He was diagnosed to have isolated aldosterone deficiency, and managed with fludrocortisone and sodium chloride orally with excellent response. He was followed up in outpatient clinic regularly and was maintaining normal serum sodium and potassium. He was thriving well (Table 2).

At 18 months of age, he was noticed to have increased pigmentation specially the lips and gum, but was thriving well. Glucocorticoid deficiency was suspected. Urgent ACTH stimulation test was carried out with $0.25 \mathrm{mg}$ synthectin. Basal ACTH $>2000 \mathrm{pg} / \mathrm{ml}$. Serum cortisol failed to rise in response to ACTH at

Disclosure. Authors have no conflict of interests, and the work was not supported or funded by any drug company.
$60 \mathrm{~min}$. Seventeen hydroxyprogesterone was normal. Testosterone and DHEAS were normal (Table 3). He was diagnosed to have primary adrenal insufficiency managed with hydrocortisone and fludrocortisone orally. At 18 months of age ultrasound done, showed right testis at the right inguinal area. He underwent orchidopexy for right undescended testis (Figure 2).

Follow-up and outcomes. He was followed up regularly in outpatient department showing normal $\mathrm{ACTH}$ and serum electrolytes, and was thriving well. His last visit was at the age of 12 years and 3 months (Table 4). His height was $134 \mathrm{~cm}$ (just below $3^{\text {rd }}$ centile), his weight was 29 kilograms (below $10^{\text {th }}$ centile).

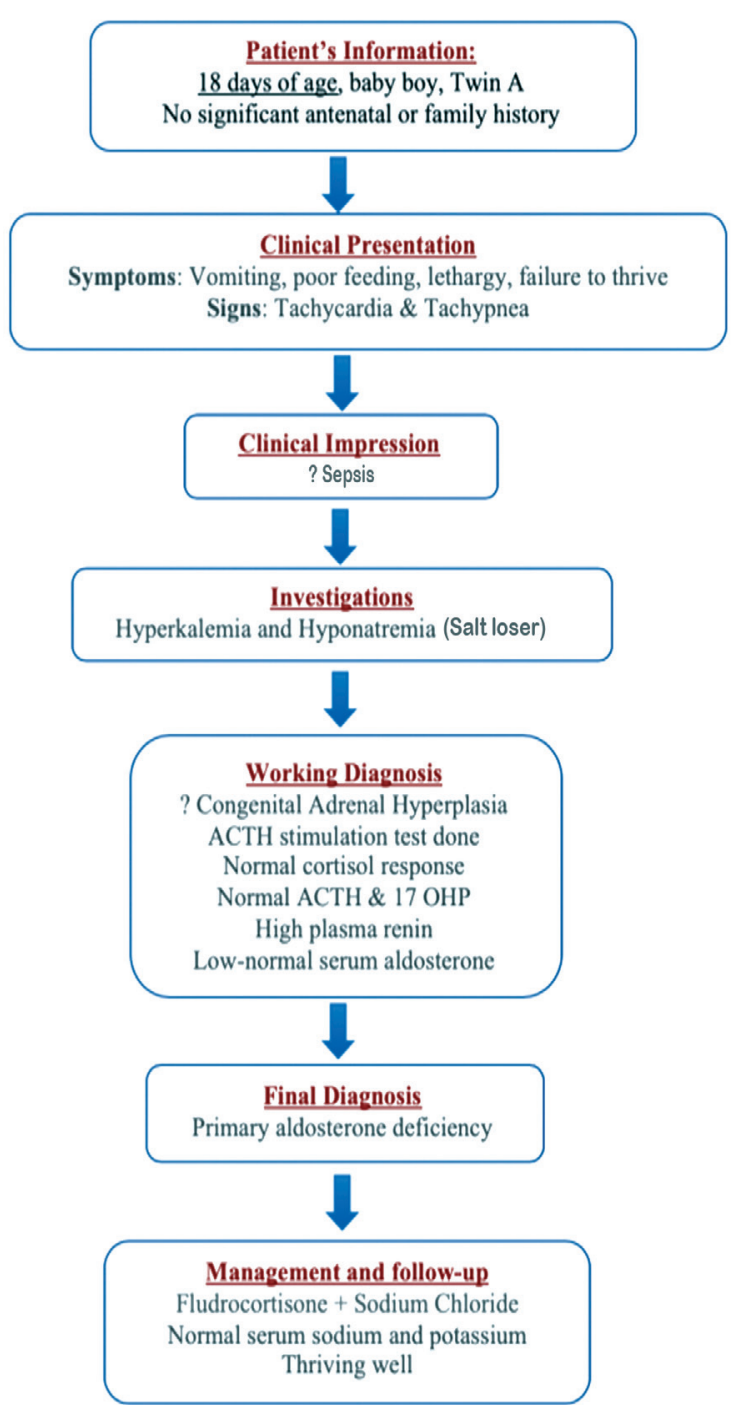

Figure 1 - Timeline summarizing the patient's (Twin A1) information, clinical presentation, clinical impression, investigations, working diagnosis, final diagnosis, and management and follow-up. 
Table 1 - Laboratory findings for twin A at 18 days of age at initial presentation.

\begin{tabular}{lcc}
\hline Indicator & Results & $\begin{array}{c}\text { Normal } \\
\text { reference }\end{array}$ \\
\hline Capillary blood gas & $\mathrm{PH}: 6.9$ & $(7.35-7.45)$ \\
Serum Na (sodium) & $128 \mathrm{mmol} / \mathrm{L}$ & $(135-148)$ \\
Serum K (potassium) & $6.2 \mathrm{mmol} / \mathrm{L}$ & $(3.5-5.0)$ \\
Serum Cl (chlorine) & $90.6 \mathrm{mmol} / \mathrm{L}$ & $(98-108)$ \\
Serum osmolality & $274.1 \mathrm{mmol} / \mathrm{L}$ & $(280-298)$ \\
Glucose & $59 \mathrm{mg} / \mathrm{dL}$ & $(70-110)$ \\
Calcium & $10.3 \mathrm{mg} / \mathrm{dL}$ & $(8.6-10.8)$ \\
Urea & $88 \mathrm{mg} / \mathrm{dL}$ & $(10-50)$ \\
Creatinine & $0.9 \mathrm{mg} / \mathrm{dL}$ & $(0.5-1.3)$ \\
Aldosterone & $5.8 \mathrm{ng} / \mathrm{dL}$ & $(5.0-132)$ \\
Plasma renin & $233 \mathrm{pg} / \mathrm{mL}$ & $(6.0-80.0)$ \\
ACTH stimulation test & & \\
ACTH & $42.8 \mathrm{pg} / \mathrm{mL}$ & $(5-60)$ \\
Serum cortisol & $9.0 \mu \mathrm{g} / \mathrm{dL}$ at 0 min & $(2.3-12.3)$ \\
17-OH progesterone & $52.4 \mu \mathrm{gg} / \mathrm{dL}$ at 60 min \\
\hline \multicolumn{2}{c}{ ACTH - adrenocorticotropic hormone } \\
\hline
\end{tabular}

Table 2 - Laboratory findings for twin A at 7 months of age. Adrenocorticotropic hormone stimulation test repeated showed normal cortisol response.

\begin{tabular}{lc} 
Indicator & Results \\
\hline Serum cortisol & $7.98 \mu \mathrm{g} / \mathrm{dL}$ at 0 minute $(2.3-12.3)$ \\
& $52.14 \mu \mathrm{d} / \mathrm{dL}$ at 60 minutes \\
17 hydroxyprogesterone & $1.0(0.25-1.5)$ at 0 minute \\
\hline
\end{tabular}

Table 3 - Laboratory findings for twin A at 18 months of age. adrenocorticotropic hormonestimulation test.

\begin{tabular}{lc}
\hline Indicator & Results \\
\hline ACTH & $>2000 \mathrm{pg} / \mathrm{mL}(5-60)$ \\
Serum cortisol & $0.502 \mu \mathrm{g} / \mathrm{dL}$ at 0 minute $(2.3-12.3)$ \\
& $0.44 \mu \mathrm{g} / \mathrm{dL}$ at 60 minutes \\
Testosterone & $<0.069 \mathrm{nmol} / \mathrm{L}(0.06-0.80)$ \\
DHEAS & $1.2 \mu \mathrm{g} / \mathrm{dL}(1.0-40.0)$ \\
\hline \multicolumn{3}{c}{ ACTH - adrenocorticotropic hormone, } \\
& DHEAS - dehydroepiandrosterone sulfate \\
\hline
\end{tabular}

Table 4 - Laboratory findings for twin A at 12 years and 3 months.

\begin{tabular}{lc}
\hline Hormones & \multicolumn{1}{c}{ Results } \\
\hline Follicle stimulating hormone & $2.38 \mathrm{U} / \mathrm{L}(0.3-4.6)$ \\
Luteinizing hormone & $0.92 \mathrm{U} / \mathrm{L}(0.04-3.6)$ \\
Testosterone (total) & $0.09 \mathrm{nmol} / \mathrm{L}(0.07-0.80)$ \\
\hline
\end{tabular}

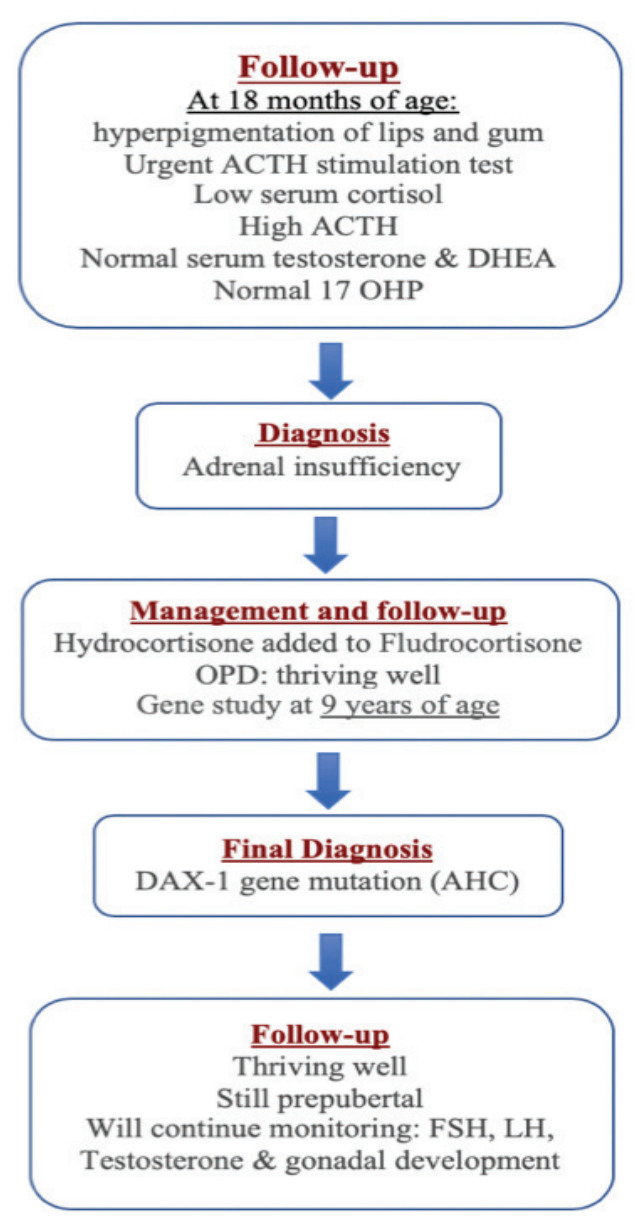

Figure 2 - Timeline summarizing the patient's (Twin A2) follow-up, diagnosis, management, final diagnosis, and follow up.

Patient information twin-B. He is now 12 years and 3 months old boy, his birth weight was $1.8 \mathrm{~kg}$. He was discharged with his mother in good condition. He was growing normally and was not having any significant illness.

Clinical findings. At the age of 9 years and 6 months, his mother brought him to endocrine clinic accompanying his twin-A brother. The mother complained that she noticed him to have progressive weight loss, fatigue, decreased activity, and progressively increasing generalized body pigmentation, which was noticed for 3 months. There was no history of vomiting, abdominal pain, or change in bowel habit. There was no history of preceding infection. On examination, he 
Table 5 - Laboratory findings for twin B at 9 years and 6 months of age as initial presentation.

\begin{tabular}{|c|c|c|}
\hline Indicator & Results & Normal reference \\
\hline Random blood sugar & $80 \mathrm{mg} / \mathrm{dL}$ & $(70-110)$ \\
\hline Blood urea nitrogen & $80 \mathrm{mg} / \mathrm{dL}$ & $(10-50)$ \\
\hline Serum $\mathrm{Na}$ (sodium) & $130 \mathrm{mmol} / \mathrm{L}$ & $(135-148)$ \\
\hline Serum K (potassium) & $6.9 \mathrm{mmol} / \mathrm{L}$ & $(3.5-5.0)$ \\
\hline Serum $\mathrm{Cl}$ (chlorine) & $95 \mathrm{mmol} / \mathrm{L}$ & $(98-107)$ \\
\hline Creatinine & $0.46 \mathrm{mg} / \mathrm{dL}$ & $(0.5-1.3)$ \\
\hline Capillary blood gas & $\begin{array}{c}\text { PH: } 7.34 \\
\text { Hco3: } 18.3\end{array}$ & $\begin{array}{l}(7.35-7.45) \\
(18-22)\end{array}$ \\
\hline ACTH & $>2000 \mathrm{pg} / \mathrm{mL}$ & $(5.0-60.0)$ \\
\hline Serum cortisol & $\begin{array}{l}3.36 \mu \mathrm{g} / \mathrm{dL} \text { at } 0 \text { minute } \\
4.11 \mu \mathrm{g} / \mathrm{dL} \text { at } 60 \text { minutes }\end{array}$ & $(1-38.0)$ \\
\hline Testosterone & $<0.087 \mathrm{nmol} / \mathrm{L}$ & $(0.1-1.04)$ \\
\hline $17-\mathrm{OH}$ progesterone & Not increased & \\
\hline
\end{tabular}

Table 6 - Laboratory findings for twin B at 12 years and 3 months.

\begin{tabular}{ll}
\hline Hormones & \multicolumn{1}{c}{ Result } \\
\hline Follicle stimulating hormone & $2.76 \mathrm{U} / \mathrm{L}(0.3-4.6)$ \\
Luteinizing hormone & $0.67 \mathrm{U} / \mathrm{L}(0.04-3.6)$ \\
Testosterone (total) & $0.09 \mathrm{nmol} / \mathrm{L}(0.07-0.80)$ \\
\hline
\end{tabular}

was alert and conscious. The Glasgow Coma Scale is $15 / 15$, lethargic, dehydrated with generalized marked hyperpigmentation. The body weight was $18 \mathrm{~kg}$ (below 3 rd centile), the height was $122 \mathrm{~cm}$ (below 5 th centile). His temperature was $36.5^{\circ} \mathrm{C}$, heart rate was $109 / \mathrm{min}$, $\mathrm{BP}$ was $104 / 59 \mathrm{mmHg}$, RR was $36 / \mathrm{min}$, and oxygen saturation was $100 \%$. Systemic examination was normal except for right undescended testis (Table 5). $\mathrm{He}$ was admitted to Pediatric Intensive Care Unit with the impression of adrenal crisis due to adrenal insufficiency. He was managed with intravenous hydrocortisone, intravenous normal saline, kayexalate, and fludrocortisone. Orchidopexy was carried out later (Figure 3).

Diagnostic assessment. As his twin-A brother was diagnosed to have primary adrenal insufficiency, AHC was suspected and blood samples for gene study were sent for both of them which proved DAX-1 mutation. After 2 months of hydrocortisone replacement the ACTH was $45.37 \mathrm{pg} / \mathrm{mL}$. At 12 years and 3 months of age his wight was $32 \mathrm{~kg}$ (above 10th centile), and his height was $135 \mathrm{~cm}$ (3rd centile) (Table 6).

Therapeutic intervention. Both brothers are now on oral hydrocortisone and fludrocortisone replacement therapy.

Follow-up and outcomes. They are thriving well, repeated hormonal evaluation, particularly serum $\mathrm{ACTH}$ was performed and is maintained within the

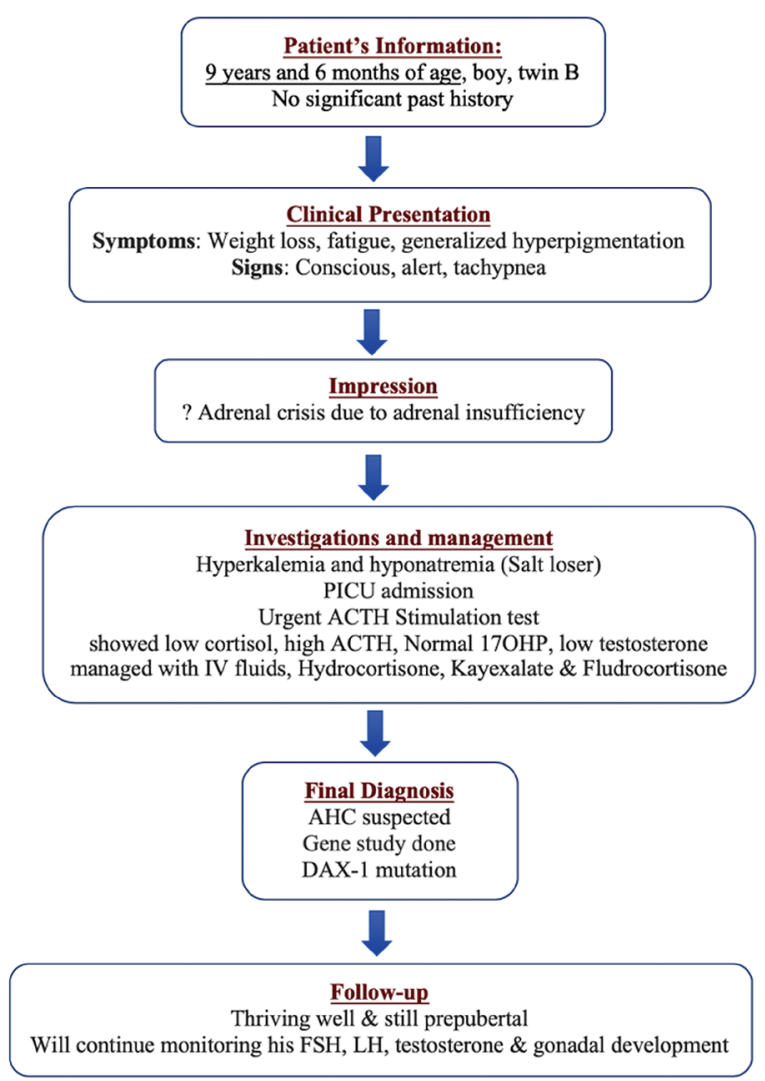

Figure 3 - Timeline summarizing the patient's (Twin B) information, clinical presentation, impression, investigation and management, final diagnosis, and follow-up.

normal reference range. Both of them have normal penile length, and Tanner stage 1 for testis and pubic hair.

Discussion. Primary adrenal insufficiency is a potentially life threatening disorder that can present with salt losing crisis or profound hypoglycemia and requires urgent resuscitation and appropriate steroid replacement. ${ }^{2}$ Primary adrenal insufficiency can occur at any age, in the neonatal period, in infancy or in childhood. ${ }^{6}$ It is difficult to diagnose AHC in a neonate because it is often misdiagnosed as the salt wasting form of congenital adrenal hyperplasia which is the most common etiology for adrenal insufficiency in this age group. ${ }^{2,4}$ In fact, both of these 2 diseases have different steroid metabolism and can be distinguished from each other by clinical manifestation and genetic features. ${ }^{4}$

Adrenal hypoplasia congenita is a rare disorder that can be inherited as an X-linked or autosomal recessive pattern. ${ }^{2,4}$ The exact incidence of AHC is not known, however, for the X-linked form, the incidence is estimated between 1:140,000 and 1:1,200,000 


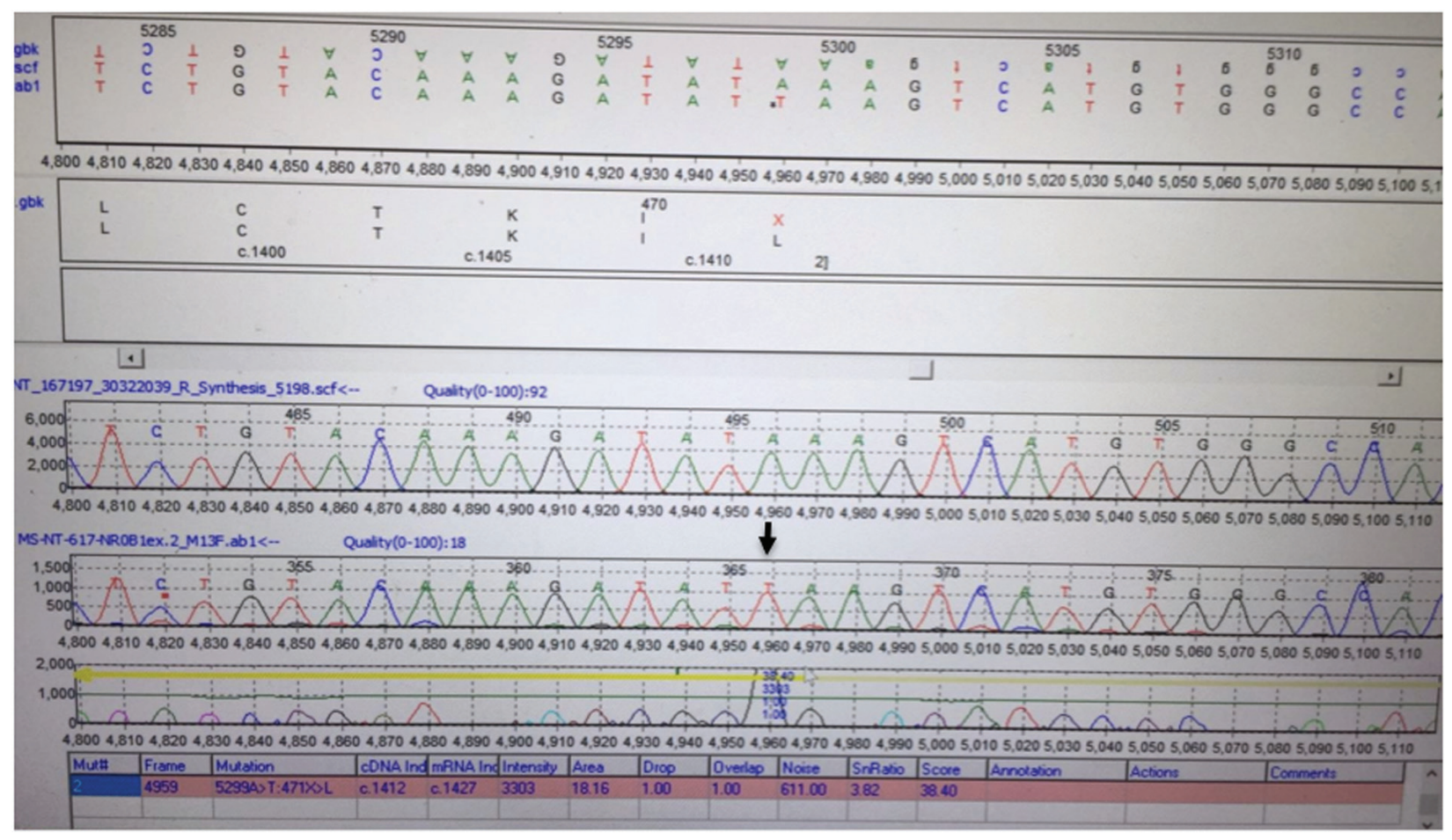

Figure 4 - Sequence chromatogram showing a bialleic nonsense mutation changing adenine to thiamine at coding position 1412 (c.A1412T) leading to change of the amino acid Leucine to a stop codon with truncation of the protein at amino acid 471 (p.471 L>X).

children. ${ }^{2}$ More than one hundred patients with DAX-1 mutations, have been described. ${ }^{5}$ DAX-1 mutations are more likely in patients with a positive family history of an affected male. ${ }^{2}$

$\mathrm{X}$-linked AHC is caused by deletions or mutations in DAX-1 gene (AHC; MIM: 300200), ${ }^{9}$ the majority of these mutations are frameshift or nonsense mutations leading to truncated DAX-1 protein. ${ }^{2}$ There is no clear evidence for a genotype-phenotype correlation between a mutation in DAX-1 (NR0B1) and its structural consequence and the clinical phenotype. The age of onset of adrenal failure can vary within the same family, suggesting that other epigenetic factors influence the clinical coarse of $\mathrm{AHC}^{1,5}$ and that's what we have described in our identical twins. Twin-A presented with salt wasting crisis in the early neonatal period which was followed with glucocorticoid deficiency after 18 months. While twin-B presented with adrenal crisis after many years (at age of 9 years and 6 months) although they were having the same mutation in DAX-1. It has also been observed that in some patients with AHC, the apparent mineralocorticoid deficiency frequently can precede glucocorticoid deficiency ${ }^{7}$ and this explained why twin-A was initially diagnosed as having isolated aldosterone deficiency. The key treatment during an acute adrenal crisis for these patients are intravenous hydrocortisone as well as normal saline with glucose solutions. These patients require lifelong replacement of glucocorticoids (physiological dose) as well as mineralocorticoids. ${ }^{2}$

Adrenal hypoplasia congenita is frequently associated with hypogonadotropic hypogonadism (HHG, MIM 1416110), the spectrum of presentation of HHG varies widely from pubertal failure to infertility. $2,3,8,9$

Mutational (genetic) analysis of DAX-1 is important in any male infant presenting with salt-losing adrenal failure, when steriodogenic disorder (congenital adrenal hyperplasia) and adrenal hemorrhage have been excluded. ${ }^{2}$ Genetic analysis of DAX-1 gene is very useful for definitive diagnosis of X-linked AHC as well as for genetic counseling in families having DAX-1 mutation with a history of unexplained death of maternal male relatives, highlighting X-linked pattern of transmission. ${ }^{10}$

We have described an identical twin with DAX-1 mutation who presented at different ages with different presentations. Twin-A presented with isolated mineralocorticoid deficiency during neonatal period, 
which was followed after 18 months with glucocorticoid deficiency. Furthermore, twin-B was totally normal till the age of 9 years and 6 months when he presented with adrenal crisis. Both of them were having undescended testis requiring orchidopexy and both are still having small testicular size at 12 years of age. They will be followed up closely for their pubertal development as they are likely to have HHG. In conclusion, gene analysis is important for the diagnosis of AHC and for genetic counseling

\section{References}

1. Yang F, Hanaki K, Kinoshita T, Kawashima Y, Nagaishi J, Kanzaki S. Late-onset adrenal hypoplasia congenita caused by a novel mutation of the DAX-1 gene. Eur J Pediatr 2009; 168: 329-331.

2. Khadilkar V, Mangtani HR, Jahagirdar RR, Khatod KA, Phadke ND, Deepa PS, et al. Entire DAX1 gene deletion in an Indian boy with adrenal hypoplasia congenita. The Indian Journal of Pediatrics 2013; 80: 631-635.

3. Darcan S, Goksen D, Ozen S, Ozkinay F, Durmaz B, Lalli E. Gonadotropin-dependent precocious puberty in a patient with X-linked adrenal hypoplasia congenita caused by a novel DAX-1 mutation. Horm Res Paediatr 2011; 75: 153-156.
4. Xu XQ, Feng YY, Yuan WX, Huang K, Liang L, Fu JF. Novel mutations in DAX1 of X-linked adrenal hypoplasia congenita over several generations in one family. Endocr Pract 2013; 19: e105-e111.

5. Ahmad I, Paterson WF, Lin L, Adlard P, Duncan P, Tolmie J, et al. A novel missense mutation in DAX-1 with an unusual presentation of X-linked adrenal hypoplasia congenita. Horm Res 2007; 68: 32-37.

6. Rojek A, Flader M, Malecka E, Niedziela M. A novel mutation in the NR0B1 (DAX1) gene in a large family with two boys affected by congenital adrenal hypoplasia. Hormones (Athens) 2014; 13: 413-419.

7. Goto M, Katsumata N. X-linked adrenal hypoplasia congenita caused by a novel intronic mutation of the DAX-1 gene. Horm Res 2009; 71: 120-124.

8. Calliari LE, Longui CA, Rocha MN, Faria CD, Kochi C, Melo $\mathrm{MR}$, et al. A novel mutation in DAX1 gene causing different phenotypes in three siblings with adrenal hypoplasia congenita. Genet Mol Res 2007; 6: 277-283.

9. Laissue L, Copelli S, Bergada I, Bergada C, Barrio G, Karaboga $S$, et al. Partial defects in transcriptional activity of two novel DAX®1 mutations in childhood冈onset adrenal hypoplasia congenita. Clinical Endocrinology 2006; 65: 681-686.

10. Ozer EA, Kaya A, Yildirimer M, Guler O, Can S, Aydinlioglu H. A novel DAX1 gene mutation in a Turkish infant with X-linked adrenal hypoplasia congenita. Eur J. Pediatr 2009; 168: 367-369. 